\title{
Letter to the Editor in Response to Khazanchi et al.
}

J Gen Intern Med 36(4):1113-4

DOI: $10.1007 / \mathrm{s} 11606-021-06594-y$

(C) Society of General Internal Medicine 2021

T o the Editor,

In a recent research report (published online on June 23, 2020), Khazanchi et al. ${ }^{1}$ describe the association of countylevel Social Vulnerability Index (SVI) ${ }^{2}$ with positive tests and deaths from COVID-19 per capita as of April 19, 2020. In an analysis unadjusted for testing frequency, age, and comorbidity burden of county residents, they found that more socially vulnerable counties (SVI in the top quartile) experience higher COVID-19 incidence and deaths compared to the least socially vulnerable (SVI in the bottom quartile), driven by the minority status and language domain. These results are interesting and similar to a prior analysis by our group (published online on April 14, 2020) ${ }^{3}$ utilizing publicly available data from counties with at least 50 confirmed COVID-19 cases as of April 4, 2020 (433 counties accounting for 283,256 cases and 6644 deaths included). After adjustment for county-level proportion of residents aged $\geq 65$ years, and comorbidities (utilizing Hierarchical Condition Category (HCC) risk scores acquired from the Centers for Medicare and Medicaid Services), ${ }^{4}$ we determined that greater SVI is associated with higher COVID-19-related Case Fatality Rate (CFR, deaths/ 100 cases), driven by the socioeconomic status, minority status/language, and housing type/transportation domains. Unlike Khazanchi et al. (1), after adjustment for covariates, we did not find that overall SVI associated with COVID-19 incidence as of April 4, 2020; although two sub-components of the SVI, socioeconomic status and minority status/language, were associated with higher incidence. In addition, understanding that a major limitation of our study was our inability to account for the contribution of county-level COVID-19 testing, we performed sensitivity analyses in the 6 states with the highest level of testing (New York, New Jersey, Washington, Massachusetts, Vermont, and Louisiana), and were able to replicate our findings. In our study, we determined that more than a quarter of the counties studied

$\overline{\text { Aditi Nayak, Shabatun J. Islam and Anurag Mehta contributed equally to }}$ this work.

Received July 7, 2020

Accepted January 1, 2021

Published online January 19, 2021 had both high social vulnerability and high CFR, with potentially devastating effects from an ensuing "disease-driven poverty trap," a vicious cycle of disease and worsening social disparity in these counties. ${ }^{5}$ Consequently, to aid public health resource allocation to these vulnerable counties, we have developed an interactive online dashboard to track COVID19 outcomes stratified by social vulnerability (http://www. eccri.emory.edu/covid/index.html), updated weekly since April 16, 2020.

Aditi Nayak, $M D^{1}$

Shabatun J. Islam, $M D^{1}$

Anurag Mehta, MD ${ }^{1}$

Arshed A. Quyyumi, $M D^{1,2}$

${ }^{1}$ Department of Medicine, Division of Cardiology, Emory University School of Medicine,

Atlanta, GA, USA

${ }^{2}$ Emory Clinical Cardiovascular Research Institute, Atlanta, GA, USA

Corresponding Author: Arshed A. Quyyumi, MD; Emory Clinical Cardiovascular Research Institute, Atlanta, GA, USA (e-mail: aquyyum@emory.edu).

Funding S.J.I. is supported by NIH grants T32 HL130O25 and T32 HLO07745-26A1. A.M. is supported by American Heart Association grant 19POST34400057 and the Abraham J. \& Phyllis Katz Foundation. A.A.Q. is supported by NIH grants 1P2OHL113451-01, 1R61HL138657-02, 1P3ODK111024-03S1, 5R01HL095479-08, 3RF1AG051633-01S2, 5R01AG042127-06, 2P01HL086773-08, U54AG062334-01, 1RO1HL141205-01, 5PO1HL101398-02, 1P2OHL113451-01, 5P01HL086773-09 1RF1AG051633-01, RO1 NS064162-01, R01 HL89650-01, HL095479-01, 1DP3DK094346$01,2 P 01 H L 086773$, and American Heart Association grant 15SFCRN23910003.

\section{Compliance with Ethical Standards:}

Conflict of Interest: The authors declare that they do not have a conflict of interest..

\section{REFERENCES}

1. Khazanchi R, Beiter ER, Gondi S, Beckman AL, Bilinski A, Ganguli I. County-level association of social vulnerability with COVID-19 cases and deaths in the USA. Journal of General Internal Medicine. 2020:1-4.

2. Flanagan BE, Hallisey EJ, Adams E, Lavery A. Measuring community vulnerability to natural and anthropogenic hazards: the Centers for Disease Control and Prevention's Social Vulnerability Index. Journal of environmental health. 2018;80(10):34. 
3. Nayak A, Islam SJ, Mehta A, Ko Y-A, Patel SA, Goyal A, et al. Impact of social vulnerability on COVID-19 incidence and outcomes in the United States. medRxiv. 2020.

4. Li P, Kim MM, Doshi JA. Comparison of the performance of the CMS Hierarchical Condition Category (CMS-HCC) risk adjuster with the Charlson and Elixhauser comorbidity measures in predicting mortality. BMC health services research. 2010;10(1):245.
5. Bonds MH, Keenan DC, Rohani P, Sachs JD. Poverty trap formed by the ecology of infectious diseases. Proceedings of the Royal Society B: Biological Sciences. 2010;277(1685):1185-92.

Publisher's Note: Springer Nature remains neutral with regard to jurisdictional claims in published maps and institutional affiliations. 